\title{
A ceramics project with deaf children: Creating Brazilian rainforest animals in clay
}

Lucia Reily lureilyoo7@gmail.com

Universidade Estadual de Campinas - Unicamp, Brasil

Reference

\section{Abstract}

Keywords
Reily, Lucia; (2012) "A ceramics project with deaf children: Creating Brazilian rainforest animals in clay", p. 211-215 . In: Barbosa, Helena; Quental, Joana [Eds]. Proceedings of the 2nd International Conference of Art, Illustration and Visual Culture in Infant and Primary Education. São Paulo: Blucher, 2015. ISSN 2318-695X, ISBN: 978-989-98185-0-7 DOI 10.5151/edupro-aivcipe-41

This paper presents a ceramics project carried out during 18 months at a university research center that works with children with disabilities. Two groups of deaf children that come to a university center for sign language instruction, speech-language therapy, literacy and visual arts education participated. We prepared the groups by talking about the rainforest animals they knew, and then explored the clay, learning to recognize tools and their functions, learning techniques. We created 12 large animals, including a toucan, a macaw, a spotted jaguar, an armadillo, an anteater, monkeys, an alligator, etc. Children worked together on each animal. The process was long; the large clay figures dried slowly. The pieces were baked at the ceramics workshop and were then painted and glazed. The children saw that challenges can be faced with success. There are worthwhile compensations for collective productions not be possible for individuals working alone.

Art project, ceramics, deaf children, visual arts, art teaching

\section{Introduction}

Art programs in regular schools and in non-educational settings in Brazil are often programmed as a series of unrelated activities that attempt to maintain participants' interest by teaching them novel techniques. This kind of approach to art teaching, in essence, conveys the idea that results can be easily achieved merely by manipulating art materials for expressive purposes. Furthermore, the proposal of craft ideas that are related to important calendar occasions, such as Springtime, Easter, Mother's Day, The day of the Indian, Carnival, Folklore month (August) and Christmas is a tradition in many schools that consider the art teacher as the person who should be responsible for school decorations by involving the children in activities around the theme of the month. Not only does this kind of approach result in a lack of cohesion in the art curriculum, but it also communicates to students that there isn't any important art content to develop, so it doesn't really matter if the school calendar constantly intrudes on the art program.

A novelty-based approach may be acceptable in a summer camp context, but for long term development in image making and image appreciation, a project-oriented program is necessary. Working from a project-based framework helps to ensure that the students learn to understand the role of planning ahead through drawing and design, anticipating their final product and working through frustration that ensue by starting over when things don't work out exactly as planned. It also means involving themselves in the final stages of production, including finishing, exhibition and group assessment (verbally or in writing). Long term projects are also important because they promote the idea that worthwhile endeavors require a certain degree of involvement and hard work. 


\section{Objectives and Context}

As long term projects gain depth and complexity, it might become necessary to call upon other knowledgeable persons in order to fulfill the project aims. When involved in new challenges, one may consult books, image sources, sites on the internet, and learn together. In this sense, a university context, such as the one where our center is located, can be a great place to carry out an interdisciplinary project involving various knowledge domains, because it is easy to reach out to undergraduate students or their teachers. In our experience, there were many people willing to share their knowledge in order to enable a group of deaf children to further their aims. While seeking technical assistance, we have found that it was important to unveil for the children that the adults who were teaching them are also learning, and that there is no shame in asking for help or showing that you do not know something.

Our aim is to present a ceramics project that was carried out with two groups of deaf children at a university center in São Paulo. This project was undertaken at the University of Campinas (Unicamp) in Campinas, Brazil - a city about 100 km from São Paulo. The Gabriel Porto Research and Rehabilitation Centre (CEPRE) is a university community service that offers, among other services, multidisciplinary support for people who have visual impairment (low vision or blindness) or deafness, across the lifespan.

We worked with two groups of 8 to 10 children in the 9 to 14 age bracket. They come to CEPRE twice a week (one group in the morning, one in the afternoon), before or after their regular school hours. All the children go to regular schools (inclusive settings) in the opposite period. Brazilian schools are morning or afternoon. Many of these children have been at CEPRE for many years; some of them live in nearby cities that do not have sign language interpreters or special education support of any kind.

The program basis is pedagogical, and a team of professionals from various fields work with the group to support their educational and language needs. Several professionals participate in this bilingual program: there are education professionals, speech and hearing therapists, the art teacher, sign language teachers (who are deaf). Brazilian sign language, called Libras (Língua Brasileira de Sinais) is the basis for interaction, though some of the children who have moderate or severe hearing loss do communicate orally.

All the children that participate in this program are deaf. Their parents receive sign language instruction and their school teachers are invited to attend sign language classes as well. Among the children, the level of hearing impairment varies from moderate to profound. Learning Libras is part of the program, even for those who speak. It is interesting to note that the children learn to differentiate whom they must sign to and who can understand speech. The children that began early on in early intervention family program sign more fluently than those who started coming to CEPRE more recently, so there are several levels of fluency in sign language. Because CEPRE is a research and development center, its mission entails professional development for undergraduate and recent graduates, who are also at different stages of sign language acquisition.

At CEPRE, visual arts is an important part of the educational program for deaf students, as it is understood that developing skills in both reading pictures and producing them will greatly contribute to their participation in the classroom. As they develop alternate ways of making meanings, deaf students should become better equipped to survive, and hopefully to succeed in the regular school system, where so much of the content is presented through verbal channels.

Having worked with deaf children for over ten years, we have observed how imaginative they are, and how easy it is for them to see figures in irregular shapes, and invent new ideas based on images seen in new positions. But we have also seen a strong tendency for copying from each other and from adult models, which is why we are always looking for ways to involve them in a project that could be especially meaningful to them, such a new long term challenges. Why should copying be a concern, one might ask.

Classical authors such as Victor Lowenfeld (1953) and Rhoda Kellogg (1969) who were broadly read in Brazil during the 1970 and 1980 s left art teachers with deep concerns about exposing young children to commercially available images, and even works of art, for that matter. They argued that such contact would contaminate their natural expressive tendencies. Copying 
$2^{\text {nd }}$ International Conference Art, Illustration and Visual Culture in Infant and Primary Education $2^{\circ}$ Congreso Internaciona

Arte, Ilustración y Cultura Visual en Educación Infantil y Primaria
${ }^{\circ}$ Congresso Internacional

de Arte, Ilustracão e Cultura Visual

na Educação Infantil e Primária

\section{How the project got started}

Figure 1. Drawing of spotted jaguar on A3 paper, by J. (13 years). Photo by the author (2010). should be discouraged at all costs in order to avoid inhibiting the child's personal artistic development. However, as the sociocultural approach in education gained ground in academic circles, researchers began to look at the issue of children's interaction with images in the environment in a completely different way. The sociocultural theory (Vygotsky, 2009; 1993) conceives of visual references altogether differently, considering the social function of images. Rather than segregate images and language, one can study how images relate to language. Rather than discouraging children from copying from each other, it becomes relevant to understand how children drawing together interact with each other's representations.

When two undergraduate students from the visual arts department at Unicamp came to us and expressed their interest in working with the deaf children at CEPRE in a ceramics project, we welcomed this idea as a wonderful opportunity. We decided to work collectively on large rain forest clay animals - approximately 40 to $45 \mathrm{~cm}$ long - the size of the ceramics oven.

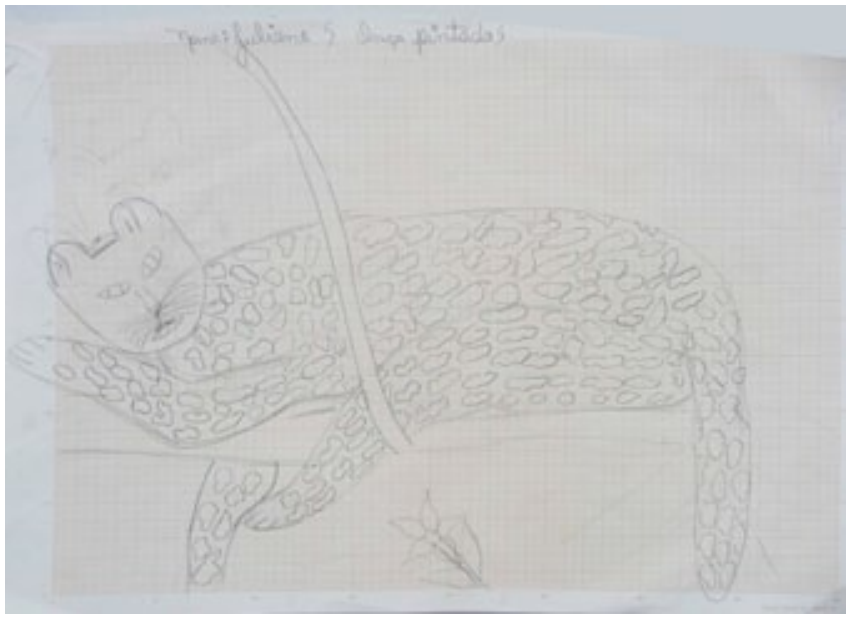

We had recently visited a school for blind children that had a trajectory that offered the children the possibility of touching rain forest animals that no longer offered any danger. We thought that we might be able to produce a similar pathway at CEPRE for blind and low vision children that come to our center.

The first stage involved uncovering the children's repertoire of rain forest animals. Which animals did they know, and what were the signs for these animals. Images are easily available on internet sites, though, naturally, we were concerned about inhibiting their creative flow by using photographs because, even though we wanted them to learn about the rain forest animals, we did not want them to worry about modeling perfect specimens, to be realistically colored.

Would they attempt to copy the photos or would they use these visual references as a springboard for their own representational agenda? In order to maintain the photographic references in their role as references, we reproduced thumbnail copies that could be at hand whenever needed, but we asked the students to draw very large animals on A3 sheets of paper, which were closer to the size that we were going to model in clay. Whenever they needed to look at details, we went back to the photographs on the computer.

Our first real challenge arose when we began to move from the two dimensional drawings each child had produced to the modeling of three dimensional animals. We decided to work with slab technique, rather than solid shapes that might prove tricky to hollow out. During the course of the project, modeling solid parts was used for smaller animal portions, such as heads and legs, while slabs were laid on curved surfaces for the body segments.

As the large animals began to emerge, we continued to introduce the children to techniques that could enhance their clay modeling skills, such as the possibility of applying various kinds of textures that were related to graphic or tactile characteristics of each animal. 
$2^{\text {nd }}$ International Conference Art. Illustration and Visual Culture in Infant and Primary Education
Figure 2. Ceramic sculpture of alligator showing texture treatment. Photo by the author (2011).
Figure 3. Anteater after first bake. Photo by the author (2011).

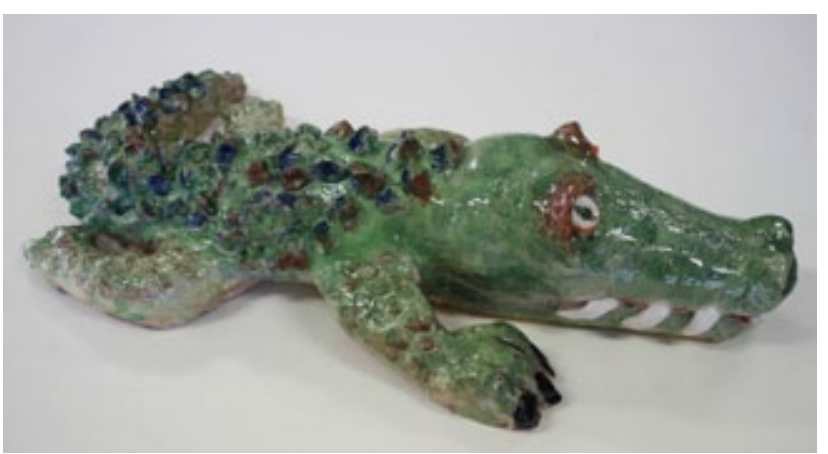

What unfolded during those many months was a fascinating process of comings and goings between the sketches the children had drawn and the final elaboration of each finished work. Sometimes small prototypes also served as sketches that were consulted. The position of the ears, of spots on the jaguar, of the kinds of claws and eyes, these and many other details could be pointed out as the large three dimensional animal was in construction.

There were, of course, different levels of involvement, and sometimes one or another of the children seemed to tire of the collective beast. They would take lumps of clay and start on parallel productions. The girls made hearts and pots, the boys made cups, animal heads, soccer insignia. Interestingly, what they had learned about correctly gluing separate clay segments together using slip stood them in good stead as they applied their recently learned skills to their personal projects.

While some animals were drying, a slow process that took several weeks, a new one was begun. Twelve animals, along with the baby turtle and baby ant eater were finished over a year and a half. The animals were: the spotted jaguar, the toucan, the parrot, the armadillo, the ant eater, the turtle, the guará fox, a fish, the boa constrictor, the coati, the alligator, and each child made a monkey individually which they got to take home

As the animals came back from the kiln, interest was renewed. Painting involved planning as well, as colors were decided on through intense group negotiations.

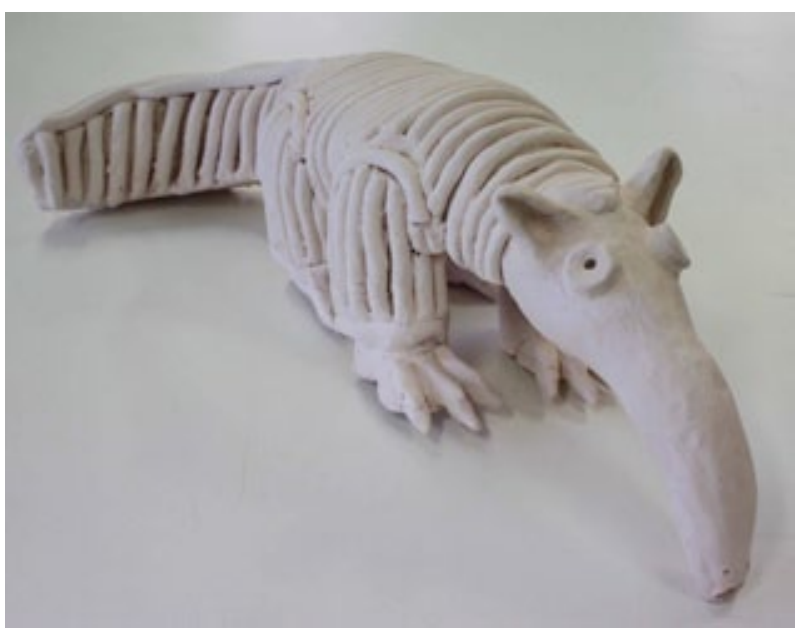

In the mean time, the project had grown and we were invited to use the animals in the monthly images of the 2012 Unicamp calendar, which involved a whole new enterprise of looking for good places to photograph each animal in the university gardens. . 1, 2). 
$2^{\text {nd }}$ International Conference Art, Illustration and Visual Culture in Infant and Primary Education
Figure 4. Cover of the 2012 Calendar. Photo by the author (2012)

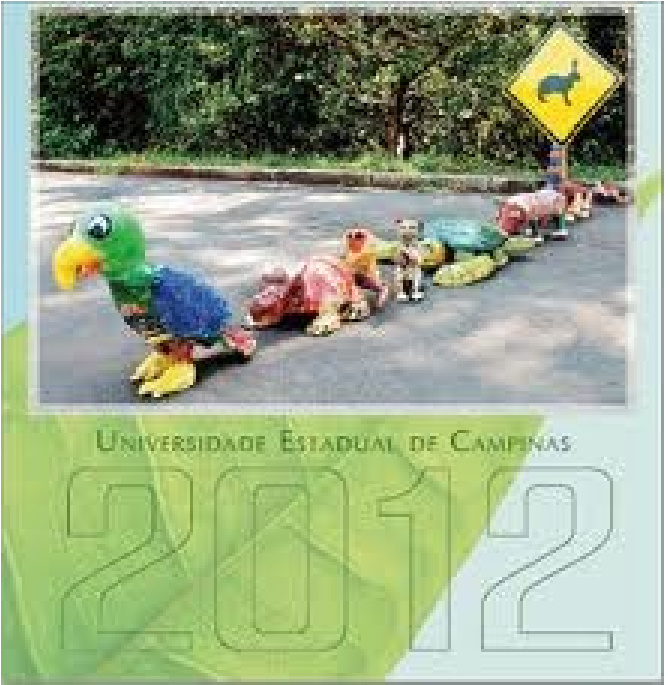

The participation of the undergraduate visual arts students was a rich opportunity for them as well as for the children. For the undergraduate students, there was the experience of learning Libras, and understanding some of the specificities of explaining and showing clay making techniques to deaf children who had had very limited experience in modeling up to then. They were able to witness how complex it can be to attempt to translate explanations that are usually presented verbally through other modalities, using metaphors and examples. For the children, the undergraduates were there to help them, and they admired them and wanted to get to know them better. The experience that the undergraduates brought to our project was essential. Without their expertise, we would not have been able to finish the animals with minimal breakage. And we would not have been able to make a mark upon the university environment in such a significant way.

\section{Bibliographical references}

Lowenfeld, V. (1953). Creative and mental growth. Oxford, England: MacMillan.

Kellogg, R. (1969). Analysing children 's art. Palo Alto, CA: National Press Books.

Vygotsky, L.S. (2009). Imaginção e criação na infância. São Paulo: Ática.

Vygotsky, L.S. (1993). The collected works of L.S. Vygotsky. Vol. 2. The fundamentals of defectology (Abnormal psychology and learning disabilities). London: Plenum Press. 